\title{
Increased Surface Expression of CD11b/CD18 (Mac-1) Is Not Required for Stimulated Neutrophil Adherence to Cultured Endothelium
}

\author{
Nicholas B. Vedder and John M. Harlan* \\ Departments of Surgery and *Medicine, University of Washington, Seattle, Washington
}

\begin{abstract}
The mechanism whereby the human neutrophil membrane heterodimer, CD11b/CD18 (Mac-1, Mo1), mediates neutrophil adherence is not known. We studied the role of CD11b/CD18 surface expression in the promotion of neutrophil adhesiveness. We found that phorbol myristate acetate (PMA), calcium ionophore (A23187), and FMLP caused a three- to sevenfold increase in surface expression of both CD11b $\left(\alpha_{M}\right)$ and CD18 $(\beta)$ as assayed by binding of MAbs 60.1 (anti-CD11b) and 60.3 (anti-CD18). Increased binding of MAbs was temporally associated with the promotion of neutrophil aggregation and adherence to cultured endothelial monolayers. Pretreatment of neutrophils with the anion channel-blocking agent, DIDS $\left(4,4^{\prime}-\right.$ diisothiocyanostilbene-2,2'-disulfonic acid), inhibited the increased surface expression of CD11b and CD18 after stimulation by PMA, A23187, or FMLP and resulted in nearly complete inhibition of neutrophil aggregation. However, pretreatment with DIDS did not diminish either PMA-, A23187-, or FMLP-stimulated neutrophil adherence to endothelial monolayers. We also observed that stimulation of granule-depleted neutrophil cytoplasts by PMA, A23187, or FMLP induced aggregation and adherence to endothelial monolayers without increasing surface expression of CD11b or CD18.

We conclude that the increased surface expression of CD11b/CD18 that occurs after stimulation is neither sufficient nor necessary for enhanced adherence to endothelium. Moreover, though both are CD11b/CD18-dependent, the mechanisms involved in neutrophil aggregation are different from those involved in neutrophil adherence to endothelium.
\end{abstract}

\section{Introduction}

Recent studies have identified a human neutrophil membrane glycoprotein complex required for numerous adhesion-dependent functions including aggregation, spreading on artificial substrates, chemotaxis, phagocytosis, and adherence to endothelium (1-12). This complex is composed of three heterodimeric subunits: LFA-1, Mac-1 (Mo1), and p150,95. Each subunit consists of a distinct heavy or $\alpha$-chain polypeptide noncovalently linked to a light or $\beta$-chain polypeptide common to

Address all correspondence to Dr. John M. Harlan, Division of Hematology, ZA-34, Harborview Medical Center, 325 Ninth Ave., Seattle, WA 98104.

Portions of this work were presented at the National Meeting of the American Federation for Clinical Research, San Diego, CA, May 1987, and appeared in Abstract form (Clin. Res. 1987. 35:434). 1987.

Received for publication 27 March 1987 and in revised form 1 July

J. Clin. Invest.

(c) The American Society for Clinical Investigation, Inc.

0021-9738/88/03/0676/07 \$2.00

Volume 81, March 1988, 676-682 all three subunits $(13,14)$. The heavy chain polypeptide of the LFA-1 subunit $\left(\alpha_{\mathrm{L}}\right)$ has been designated CD11a, that of the Mac-1 subunit $\left(\alpha_{M}\right)$ has been designated CD11b, and that of the p150,95 subunit $\left(\alpha_{X}\right)$ has been designated CD11c by the Third International Workshop on Leukocyte Differentiation Antigens (15). The common $\beta$-chain polypeptide has been designated CD18 (15).

Patients with a congenital deficiency of CD11/CD18 suffer from recurrent bacterial infections and an inability to suppurate (reviewed in reference 16). These patients' neutrophils demonstrate in vitro defects in adhesion-dependent functions that can be reproduced in normal neutrophils by the addition of MAbs directed to function-related epitopes of the glycoprotein complex (1-7). The CD11b/CD18 subunit has been shown to play an important role in neutrophil adherence to vascular endothelium, a critical early event in neutrophil emigration during the acute inflammatory response. The MAbs anti-CD11b (60.1) and anti-CD18 (60.3), recognizing respectively the CD1 $1 \mathrm{~b}$ and CD18 polypeptides (2), have been shown in vitro to prevent stimulated neutrophil aggregation and adherence to endothelial monolayers $(1,3,5)$.

The mechanism by which CD1 1b/CD18 augments neutrophil adhesiveness in response to stimulation is not known. It has been shown that in unstimulated neutrophils, the CD11b polypeptide exists both on the cell surface and in far greater quantities within the secondary and/or tertiary granules. After stimulation, contents of these granules are translocated to the cell surface, resulting in a 3- to 10-fold increase in surface-associated CD11b (assayed as increased binding of CD1 lb-specific MAb) (12, 17-19). It has been suggested that this increase in surface expression may play an important role in the mechanism of enhanced neutrophil adhesiveness (12, 17-20). This hypothesis has not been critically examined, however.

To investigate the role of increased CD11b/CD18 surface expression in stimulated neutrophil adherence we employed the anion channel-blocking agent, $\operatorname{DIDS}^{1}\left(4,4^{\prime}\right.$-diisothiocyanostilbene-2,2'-disulfonic acid), which blocks neutrophil degranulation (21-24). We show that pretreatment of neutrophils with DIDS effectively blocks the increased surface expression of $\mathrm{CD} 11 \mathrm{~b} / \mathrm{CD} 18$ in response to phorbol myristate acetate (PMA), A23187, or FMLP. Neutrophil aggregation after stimulation by these agents is also inhibited by pretreatment with DIDS. However, stimulated neutrophil adherence to endothelium is not inhibited but in fact is potentiated when increased surface expression of CD11b/CD18 is blocked by DIDS.

We also show that neutrophil cytoplasts, devoid of cytoplasmic granules, can be stimulated by PMA, A23187, or FMLP to increase their adherence to endothelium despite

1. Abbreviations used in this paper: BEC, bovine aortic endothelial cells; DIDS, 4,4'-diisothiocyanostilbene-2,2'-disulfonic acid; HBSS-, Hanks' balanced salt solution without calcium or magnesium; HEC, human umbilical vein endothelial cells; MPO, myeloperoxidase. 
being incapable of increasing surface expression of CD11b or CD18.

These findings indicate that the increase in surface expression of CD11b and CD18 that occurs with neutrophil stimulation is neither sufficient nor necessary for enhanced adherence to endothelium.

\section{Methods}

Cell culture. Human umbilical vein endothelial cells (HEC) and bovine aortic endothelial cells (BEC) were prepared by collagenase treatment of vessels as described $(25,26)$. All cell lines were maintained in endotoxin-free RPMI 1640 medium (M. A. Bioproducts, Walkersville, MD) supplemented with $20 \%$ FCS with heparin $(90 \mathrm{mg} / \mathrm{ml})$ and endothelial cell growth factor as described by Thornton et al. (27). Endothelial cell growth factor was prepared from bovine hypothalamus as described by Maciag et al. (28). HEC and BEC were harvested with $0.05 \%$ trypsin and $0.02 \%$ EDTA in HBSS (Gibco Laboratories, Gibco Div., Chagrin Falls, $\mathrm{OH}$ ) without calcium or magnesium (HBSS-). The cells were then plated in 11-mm-diam wells in 48-well plates (Cluster 3548; Costar, Data Packaging Corp., Cambridge, MA) at 5 $\times 10^{4}$ cells/well in RPMI 1640 with $20 \%$ FCS. Visually confluent monolayers were formed after overnight incubation.

Neutrophil isolation and labeling. Peripheral blood from healthy donors was obtained by venipuncture and collected in syringes containing heparin, $10 \mathrm{U} / \mathrm{ml}$. Neutrophils were isolated by Ficoll-Hypaque density gradient centrifugation followed by $3 \%$ dextran sedimentation and hypotonic saline lysis of erythrocytes (29). The resulting cells were $>95 \%$ neutrophils and $>95 \%$ viable by trypan blue exclusion. The cells were then suspended in HBSS- for use in aggregation experiments and for analysis by immunofluorescence flow cytometry. Cells for adherence experiments were suspended in PBS and labeled with ${ }^{51} \mathrm{Cr}$ as sodium chromate (New England Nuclear, Boston, MA) $1 \mu \mathrm{Ci} / 10^{6}$ cells for $60 \mathrm{~min}$ at $37^{\circ} \mathrm{C}(30)$. After labeling, the cells were washed three times in PBS. Immunofluorescence flow cytometry, aggregation, and adherence experiments were all performed simultaneously on neutrophils from the same preparation.

Preparation of neutrophil cytoplasts. Neutrophil cytoplasts were prepared according to Korchak et al. (31). Briefly, purified neutrophils were suspended in $12.5 \%$ Ficoll-70 in HBSS- with cytochalasin B, 5 $\mu \mathrm{g} / \mathrm{ml}$, and incubated at $37^{\circ} \mathrm{C}$ for $5 \mathrm{~min}$. This suspension was then layered on a $37^{\circ} \mathrm{C}$ discontinuous Ficoll gradient $(12.5 ; 16 ; 25 \%$ in HBSS- with $5 \mu \mathrm{g} / \mathrm{ml}$ cytochalasin B throughout) and centrifuged at $81,000 \mathrm{~g}$ for $30 \mathrm{~min}$ in a model L2-65B ultracentrifuge with an SW-28 swinging bucket rotor (Beckman Instruments, Palo Alto, CA). The cytoplast band was aspirated and washed three times in HBSS-. Cytoplasts were then used in the same immunofluorescence, aggregation, and adherence assays as normal neutrophils, using cytoplasts from the same preparation in all three assays simultaneously.

Immunofluorescence flow cytometry. Neutrophils were suspended in HBSS - $\left(5 \times 10^{6}\right.$ cells $\left./ \mathrm{ml}\right)$ with or without DIDS $(250 \mu \mathrm{M})$ at room temperature for $15 \mathrm{~min}$. Then, $5 \times 10^{5}$ cells were placed into polypropylene tubes $(12 \times 75 \mathrm{~mm}$; Falcon Labware, Becton, Dickinson and Co., Oxnard, CA). Cells were then stimulated with HBSS- (control), PMA (100 ng/ml final concentration), A23187 (10 ${ }^{-5} \mathrm{M}$ final concentration), or FMLP $\left(10^{-5} \mathrm{M}\right.$ final concentration) for $30 \mathrm{~min}$ at $37^{\circ} \mathrm{C}$ in a shaking water bath. Unstimulated controls were placed directly on ice. Next, $50 \mu \mathrm{l}$ of heat-inactivated adult bovine serum was added and the cells incubated at $4^{\circ} \mathrm{C}$ for $30 \mathrm{~min}$. After this, a saturating concentration $(40 \mu \mathrm{g} / \mathrm{ml})$ of MAb or HBSS - (control) was added and the cells incubated for an additional $30 \mathrm{~min}$ at $4^{\circ} \mathrm{C}$. After two washes in cold HBSS -, the cells were suspended in $25 \mu$ l of a saturating concentration of detecting antibody (FITC goat anti-mouse IgG; Tago Inc., Burlingame, CA) for $30 \mathrm{~min}$ at $4^{\circ} \mathrm{C}$. After two final washes in cold HBSS-, the cells were fixed in $1 \%$ paraformaldehyde.
Analysis was performed using a fluorescence activated cell sorter (B-D FACS-440; Becton-Dickinson \& Co., Sunnyvale, CA) with a $50-\mu \mathrm{m}$ orifice. The results were displayed as single parameter histograms with the $x$-axis representing the $\log _{10}$ of the relative fluorescence intensity per cell and the $y$-axis representing the number of cells. Peak fluorescence for each histogram was also converted to a linear number for tabular display.

Neutrophil aggregation. Aggregometry was performed by the nephelometric technique of Craddock (32) using a model 330 platelet aggregometer (Chrono-Log Corp., Havertown, PA). Neutrophils were suspended in HBSS - at a concentration of $20 \times 10^{6} / \mathrm{ml}$. The cells were treated with cytochalasin B $(5 \mu \mathrm{g} / \mathrm{ml})$ and either medium or DIDS (250 $\mu \mathrm{M})$. After standing at room temperature for $15 \mathrm{~min}, 425-\mu 1$ aliquots were transferred to silicone coated cuvettes and brought to $37^{\circ} \mathrm{C}$. These were then placed in the aggregometer with a teflon stirring bar and stirred for $1 \mathrm{~min}$ after the addition of $25 \mu \mathrm{l}$ of $\mathrm{CaCl}_{2} / \mathrm{MgCl}_{2}$ solution for a final concentration of $1 \mathrm{mM} \mathrm{Ca}^{++}, 0.5 \mathrm{mM} \mathrm{Mg}^{++}$. Then, 50 $\mu l$ of HBSS- (control), PMA (to final concentration $100 \mathrm{ng} / \mathrm{ml}$ ), A23187 (to final concentration $10^{-5} \mathrm{M}$ ), or FMLP (to final concentration $10^{-5} \mathrm{M}$ ) was added and the change in light transmission was recorded over time. A 1:1 mixture of cells with HBSS- was used as a cell-poor calibration standard. The results were confirmed by examining neutrophil aggregation microscopically in $11-\mathrm{mm}$-diam wells using the same reagents, volumes, and concentrations.

Adherence assay. The purified ${ }^{51} \mathrm{Cr}$-labeled neutrophils were suspended in endotoxin-free RPMI 1640 medium with 5\% FCS at a concentration of $2 \times 10^{6} \mathrm{cells} / \mathrm{ml}$ (FCS prevented nonspecific detachment of endothelial cell monolayers from the tissue culture plastic). The cells were then treated with medium (control) or DIDS $(250 \mu \mathrm{M})$ at room temperature for $15 \mathrm{~min}$. The 48 -well HEC or BEC plate was decanted and fresh medium was added: RPMI 1640 with 5\% FCS with or without $250 \mu \mathrm{M}$ DIDS. Then, $200 \mu \mathrm{l}$ of the neutrophil suspension was added to each well followed immediately by $50 \mu \mathrm{l}$ of medium (control), PMA (final concentration $100 \mathrm{ng} / \mathrm{ml}$ ), A23187 (final concentration $10^{-5} \mathrm{M}$ ), or FMLP (final concentration $10^{-5} \mathrm{M}$ ). Plates were incubated for $30 \mathrm{~min}$ at $37^{\circ} \mathrm{C}$ in a $5 \% \mathrm{CO}_{2}$ incubator. Nonadherent neutrophils were removed with two well volume exchanges of PBS with 5\% FCS. Adherent neutrophils were lysed with $1 \mathrm{~N} \mathrm{NH}_{4} \mathrm{OH}$. The lysates were then counted in a gamma spectrophotometer (Micromedic ME Plus, Micromedic Systems Inc., Horsham, PA). Neutrophil adherence was calculated for each well and expressed as the percentage of the ${ }^{51} \mathrm{Cr}$ counts that remained adhered to the endothelial monolayer: $\%$ adherence $=\left({ }^{51} \mathrm{Cr} \mathrm{cpm}\right.$ in lysate $) /\left(\right.$ total ${ }^{51} \mathrm{Cr} \mathrm{cpm}$ added $) \times 100$.

Total ${ }^{{ }^{5} 1} \mathrm{Cr} \mathrm{cpm}$ added was determined by counting $200-\mu \mathrm{l}$ samples of the neutrophil suspension. The results were confirmed qualitatively by microscopic analysis. In experiments using unlabeled cells, results were quantified by counting adherent neutrophils in photomicrographs and by assaying for myeloperoxidase (MPO) activity as described by Lundquist and Josefsson (33).

$M A b$. Murine $\mathrm{MAb}, 60.1$, is an $\mathrm{IgG}_{1}$ antibody that recognizes a functional epitope on the CD1 lb polypeptide (2). Murine MAb, 60.3, is an $\mathrm{IgG}_{2 \mathrm{a}}$ antibody that recognizes a functional epitope on CD18 (2, 4). MAb, 60.5, is an $\operatorname{IgG}_{2 \mathrm{a}}$ antibody that recognizes an HLA class I framework antigen present on all peripheral leukocytes and human endothelial cells (4). MAbs 60.3 and 60.5 were purified on staphylococcal protein A columns and MAb 60.1 was purified by ammonium sulfate precipitation. MAbs $60.1,60.3$, and 60.5 were gifts of Dr. Patrick Beatty, Puget Sound Blood Center, Seattle, WA.

Reagents. DIDS, PMA, FMLP, heparin, dextran, Ficoll-70, and cytochalasin B were obtained from Sigma Chemical Co., St. Louis, MO. A23187 was obtained from Calbiochem-Behring Diagnostics, American Hoechst Corp., San Diego, CA. Ficoll-Hypaque was obtained from Pharmacia Fine Chemicals, Div. of Pharmacia Inc., Piscataway, NJ. FCS and adult bovine serum were obtained from HyClone Laboratories, Sterile Systems Inc., Logan, UT.

Statistics. Results were expressed as mean $\pm \mathrm{SE}$ and significance was determined by unpaired $t$ test. 


\section{Results}

DIDS blocks increased surface expression of CD11b/CD18 (Mac-1) in stimulated neutrophils. Stimulation of neutrophils with PMA, A23187, or FMLP resulted in a three- to sevenfold increase in the binding of MAb 60.1 (directed to the CD11b polypeptide) compared with unstimulated controls, as assayed by immunofluorescence flow cytometry. This increase was blocked to below control level by pretreatment of the cells with DIDS (Fig. 1 and Table I). PMA, A23187, or FMLP similarly increased binding of MAb 60.3 (directed to CD18) by three- to six-fold over unstimulated controls. Again, DIDS inhibited this increase by $92 \%$ for PMA, $76 \%$ for A23187, and by $88 \%$ for FMLP (Table I). DIDS alone had no effect on binding of MAbs 60.1 or 60.3 to unstimulated neutrophils (Table I).

The same results were obtained when stimulation and staining were performed in RPMI with 5\% FCS. The presence of $\mathrm{Mg}^{++}$in RPMI and in FCS, however, allowed neutrophils to aggregate when stimulated with PMA and resulted in flattened, though appropriately shifted, curves (data not shown). The effect of DIDS was reversible since washing the cells after treatment with DIDS allowed maximal binding of MAbs 60.1 and 60.3 after stimulation with A23187 to the level of nonDIDS-treated cells (data not shown). The binding of isotypematched MAb 60.5, directed to a common HLA framework antigen, and present at a density similar to CD1 $1 \mathrm{~b}$ and $\mathrm{CD} 18$ in resting cells (4), remained constant with all treatments (Fig. 1).

DIDS blocks neutrophil aggregation. PMA, A23187, and FMLP all induced neutrophil aggregation as measured nephelometrically and by microscopic observation. Pretreatment of neutrophils with DIDS $(250 \mu \mathrm{M})$ blocked aggregation in response to either PMA, A23187, or FMLP (Fig. 2 and Table I).

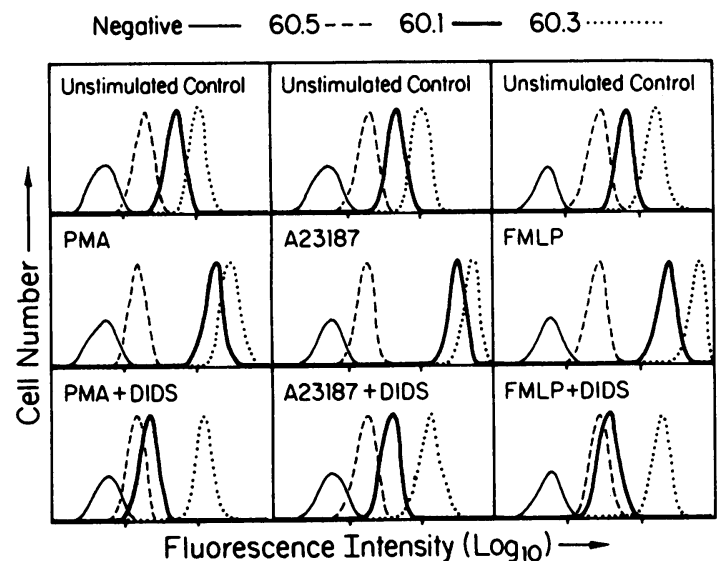

Figure 1. DIDS inhibits increased surface expression of CD11b and CD18. Neutrophils were pretreated with medium or medium containing DIDS $(250 \mu \mathrm{M})$ then stimulated with HBSS- (control), PMA $(100 \mathrm{ng} / \mathrm{ml}), \mathrm{A} 23187\left(10^{-5} \mathrm{M}\right)$, or FMLP $\left(10^{-5} \mathrm{M}\right)$. The surface binding of MAbs 60.1 and 60.3 were measured by indirect immunofluorescence and are compared with the binding of MAb 60.5 (antiHLA class I framework antigen). The horizontal axis represents the amount of antibody binding per cell $\left(\log _{10}\right)$ and the vertical axis represents the number of cells. The first curves (Negative) represent background nonspecific binding of detecting antibody to cells not exposed to any MAb. Similar results were obtained in five separate experiments.
Table I. Effect of DIDS on Surface Expression of CD11b/CD18, Aggregation, and Adherence to HEC

\begin{tabular}{|c|c|c|c|c|}
\hline \multirow[b]{2}{*}{ Stimulant } & \multicolumn{2}{|c|}{$\begin{array}{l}\text { Fold increase in surface } \\
\text { expression over } \\
\text { unstimulated control }\end{array}$} & \multirow{2}{*}{$\begin{array}{l}\text { Aggregation } \\
\Delta T \text { over } \\
\text { control }\end{array}$} & \multirow{2}{*}{$\begin{array}{c}\% \\
\text { Adherence } \\
\text { to HEC }\end{array}$} \\
\hline & CD11b & $\mathrm{CD} 18$ & & \\
\hline Control & $1.0 \pm 0.0^{*}$ & $1.0 \pm 0.0^{*}$ & $0 \pm 0^{*}$ & $2 \pm 0$ \\
\hline Control + DIDS & $1.0 \pm 0.2$ & $1.1 \pm 0.1$ & $0 \pm 0$ & $5 \pm 1^{6}$ \\
\hline PMA (100 ng/ml) & $4.6 \pm 0.9$ & $3.5 \pm 0.5$ & $70 \pm 3$ & $41 \pm 2$ \\
\hline PMA + DIDS & $0.4 \pm 0.1^{8}$ & $1.2 \pm 0.1^{8}$ & $7 \pm 1^{11}$ & $49 \pm 3^{\ddagger}$ \\
\hline A23187 $\left(10^{-5} \mathrm{M}\right)$ & $6.6 \pm 1.1$ & $6.4 \pm 0.6$ & $64 \pm 4$ & $22 \pm 2$ \\
\hline A23187 + DIDS & $0.8 \pm 0.1^{8}$ & $2.2 \pm 0.1^{8}$ & $5 \pm 2^{11}$ & $32 \pm 2^{\prime \prime}$ \\
\hline FMLP $\left(10^{-5} \mathrm{M}\right)$ & $3.2 \pm 0.4$ & $3.4 \pm 0.4$ & $64 \pm 5$ & $10 \pm 3$ \\
\hline FMLP + DIDS & $0.5 \pm 0.3^{8}$ & $1.3 \pm 0.1^{8}$ & $4 \pm 2^{\| \prime}$ & $25 \pm 2^{\prime \prime}$ \\
\hline
\end{tabular}

DIDS $(250 \mu \mathrm{M})$ blocks the stimulated increase in surface expression of CD1 $1 \mathrm{~b}$ and CD18 and blocks neutrophil aggregation, yet potentiates stimulated neutrophil adherence to HEC. Increase in surface expression was calculated from histograms as in Fig. 1 by converting mean fluorescence for each curve to a linear format and expressing the result relative to unstimulated controls. Aggregation was calculated from tracings as in Fig. 2 using an arbitrary linear scale to express peak aggregation responses $(\Delta T)$ relative to unstimulated controls. Results above represent means $\pm S E$ of five separate experiments for PMA and A23187; three separate experiments for FMLP.

* By definition.

${ }^{\ddagger} P<0.05$.

$P<0.005$.

" $P<0.0005$ (compared with stimulant without DIDS).

When aggregation was performed in RPMI with FCS, the inhibition effect of DIDS was still observed (data not shown). Non-cytochalasin B-treated cells demonstrated an attenuated aggregation response that was also blocked by DIDS (data not shown).

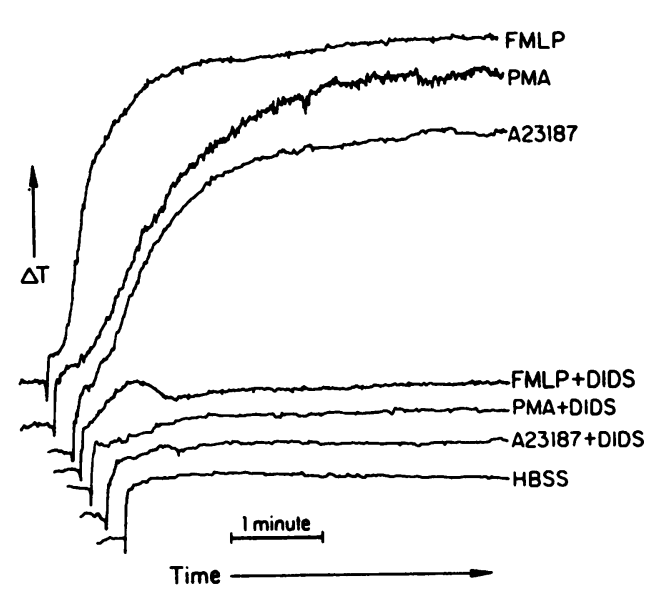

Figure 2. DIDS inhibits neutrophil aggregation induced by PMA, A23187, or FMLP. Aggregation was recorded as an increase in light transmission $(\Delta T)$ over time after addition of HBSS - (control), PMA $(100 \mathrm{ng} / \mathrm{ml})$, A23187 $\left(10^{-5} \mathrm{M}\right)$, or FMLP $\left(10^{-5} \mathrm{M}\right)$ to neutrophils suspended in HBSS or HBSS containing DIDS $(250 \mu \mathrm{M})$. Addition of reagent is indicated by the initial small upward deflection representing the dilution artifact. Similar results were obtained in five separate experiments. 
DIDS does not block neutrophil adherence to endothelium. Results of adherence experiments with HEC are shown in Table I. Unstimulated neutrophils demonstrated minimal adherence to HEC monolayers. PMA, A23187, and FMLP markedly increased neutrophil adherence to HEC. Pretreatment of neutrophils with DIDS $(250 \mu \mathrm{M})$ did not diminish this stimulated adherence, but in fact potentiated adherence.

Similar results were obtained with BEC: in five experiments, unstimulated adherence was $3 \pm 0 \%$ without DIDS and $6 \pm 1 \%$ with DIDS; PMA-stimulated adherence in non-DIDStreated neutrophils was $64 \pm 3$ vs. $72 \pm 3 \%$ in DIDS-treated neutrophils $(P<0.05)$; A23187-stimulated adherence in nonDIDS-treated neutrophils was $26 \pm 2$ vs. $50 \pm 4 \%$ in DIDStreated neutrophils $(P<0.0005)$.

To control for the possibility that DIDS might be exerting a proadhesive effect via the endothelial cell, we examined neutrophil adherence to albumin-coated tissue culture plastic. These results were similar to those observed with BEC or HEC: in three experiments, unstimulated adherence was $4 \pm 1 \%$ without DIDS and $12 \pm 2 \%$ with DIDS; PMA-stimulated adherence in non-DIDS-treated neutrophils was $56 \pm 2 \%$ vs. $64 \pm 3 \%$ in DIDS-treated neutrophils $(P<0.05)$; A23187-stimulated adherence in non-DIDS-treated neutrophils was $44 \pm 4 \%$ vs. $53 \pm 4 \%$ in DIDS-treated neutrophils $(P=0.13)$; and FMLP-stimulated adherence in non-DIDS-treated neutrophils was $27 \pm 3 \%$ vs. $38 \pm 3 \%$ in DIDS-treated neutrophils ( $P$ $<0.05$ ).

To demonstrate that adherence in the presence of DIDS was still occurring through a CD1 lb/CD18-dependent mechanism, we examined the effect of the MAb, 60.3, on adherence. Addition of MAb $60.3(40 \mu \mathrm{g} / \mathrm{ml})$ blocked both PMA- and A23187-stimulated neutrophil adherence with or without DIDS to below the level of unstimulated controls (for example: PMA + DIDS resulted in only $1 \%$ adherence to BEC in the presence of MAb 60.3 , compared with $55 \pm 5 \%$ without MAb 60.3). Similar results were obtained with the MAb, 60.1. Addition of MAb $60.1(40 \mu \mathrm{g} / \mathrm{ml})$ blocked PMA-, A23187-, and
FMLP-stimulated neutrophil adherence with or without DIDS to below the level of unstimulated controls (for example: PMA + DIDS resulted in only $1 \%$ adherence to BEC in the presence of MAb 60.1, compared with 55 $\pm 5 \%$ without MAb 60.1).

To control for possible unaccounted translocation of $\mathrm{CD} 11 \mathrm{~b}$ or $\mathrm{CD} 18$ during ${ }^{51} \mathrm{Cr}$ labeling at $37^{\circ} \mathrm{C}$ (34) we examined adherence to BEC using neutrophils immediately after their isolation. Quantitative evaluation by microscopic inspection (counting adherent neutrophils in photomicrographs) confirmed the data obtained with ${ }^{51} \mathrm{Cr}$-labeled cells. With non-DIDS-treated neutrophils PMA induced an 8.0-fold increase in adherence relative to unstimulated controls vs. a 10.0-fold increase with DIDS-treated cells. Similarly, A23187 induced a 4.7-fold increase in adherence relative to unstimulated controls with non-DIDS-treated neutrophils vs. a 4.9fold increase with DIDS-treated cells. In another experiment, adherent neutrophils were quantified by assaying for MPO activity. PMA induced a 3.5 \pm 0.1 -fold increase in MPO activity relative to unstimulated controls with non-DIDS-treated neutrophils vs. a $4.9 \pm 0.4$-fold increase with DIDS-treated cells $(P<0.005)$. Similarly, A23187 induced a $3.1 \pm 0.1$-fold increase in MPO activity relative to unstimulated controls with non-DIDS-treated neutrophils vs. a $4.2 \pm 0.2$-fold increase with DIDS-treated cells $(P<0.0005)$.

Stimulated neutrophil cytoplasts aggregate and adhere to endothelium without increasing surface expression of CD11b or $C D 18$. To further examine the role of $C D 11 \mathrm{~b} / C D 18$ surface expression in neutrophil aggregation and adherence to endothelium, we prepared neutrophil cytoplasts that are devoid of cytoplasmic granules (31) and therefore incapable of increasing surface expression of $\mathrm{CD} 1 \mathrm{~b}(35,36)$ or $\mathrm{CD} 18$. We found that unstimulated cytoplasts, like neutrophils, adhered minimally to HEC monolayers. However, with stimulation by either PMA, A23187, or FMLP, adherence was markedly increased (Table II). As with neutrophils, this increased adherence was blocked by coincubation with MAb 60.3 (Table II). We also observed that cytoplasts aggregated in response to

Table II. Effect of Stimulation on Neutrophil Cytoplast Surface Expression of CD11b/CD18, Adherence to HEC, and Aggregation

\begin{tabular}{|c|c|c|c|c|c|c|c|}
\hline \multirow[b]{2}{*}{ Stimulant } & \multirow[b]{2}{*}{ Experiment } & \multicolumn{2}{|c|}{$\begin{array}{c}\text { Fold increase in surface } \\
\text { expression over } \\
\text { unstimulated control } \\
\end{array}$} & \multicolumn{2}{|c|}{$\%$ Adherence to HEC } & \multicolumn{2}{|c|}{ Aggregation $\Delta \mathrm{T}$ over control } \\
\hline & & CD11b & CD18 & (-)MAb 60.3 & $(+)$ MAb 60.3 & (-)MAb 60.3 & $(+)$ MAb 60.3 \\
\hline \multirow[t]{2}{*}{ Control } & 1 & $0.0^{*}$ & $0.0^{*}$ & $7 \pm 1$ & $5 \pm 0$ & $0^{*}$ & \\
\hline & 2 & $0.0^{*}$ & $0.0^{*}$ & $9 \pm 1$ & $4 \pm 0$ & $0^{*}$ & \\
\hline \multirow[t]{2}{*}{ PMA (100 ng/ml) } & 1 & 0.8 & 1.0 & $17 \pm 2^{\S}$ & $7 \pm 1$ & 64 & 5 \\
\hline & 2 & 1.0 & 0.8 & $22 \pm 6^{\ddagger}$ & $7 \pm 2$ & 75 & 17 \\
\hline \multirow[t]{2}{*}{ A23187 $\left(10^{-5} \mathrm{M}\right)$} & 1 & 1.4 & 1.0 & $14 \pm 1^{8}$ & $3 \pm 0$ & & \\
\hline & 2 & 1.0 & 1.0 & $14 \pm 3^{\ddagger}$ & $0 \pm 0$ & & \\
\hline \multirow[t]{2}{*}{$\operatorname{FMLP}\left(10^{-5} \mathrm{M}\right)$} & 1 & 1.3 & 1.1 & $12 \pm 1^{8}$ & $5 \pm 0$ & & \\
\hline & 2 & 1.0 & 1.1 & $22 \pm 3^{\S}$ & $15 \pm 2$ & & \\
\hline
\end{tabular}

Stimulated neutrophil cytoplasts aggregate and adhere to endothelium but do not increase surface expression of CD11b or CD18. Stimulated cytoplast aggregation and adherence to endothelium are blocked by coincubation with MAb $60.3(40 \mu \mathrm{g} / \mathrm{ml})$. Surface expression was calculated as in Table I. Percent adherence is expressed as mean \pm SE of eight replicate wells (four replicate wells with MAb 60.3). Results of two separate experiments are shown. All assays in each experiment were performed with cytoplasts from the same preparation. * By definition.

${ }^{\ddagger} P<0.05$. $P<0.005$ (compared with unstimulated control). 
PMA stimulation, as measured nephelometrically (Table II) and by microscopic examination. This aggregation response was also blocked by MAb 60.3 (Table II). Cytoplasts from the same preparation that aggregated and adhered to HEC, however, did not increase surface expression of CD1 $1 \mathrm{~b}$ or CD18 in response to the same stimuli under the same conditions (Table II).

\section{Discussion}

The central role of the CD11b/CD18 membrane glycoprotein subunit in adhesion-dependent neutrophil functions is well documented (1-12). MAbs directed against components of the subunit have been shown in vitro to interfere with neutrophil aggregation, spreading on plastic, antibody-dependent cellular cytotoxicity, chemotaxis, phagocytosis, and adherence to endothelium (1-7). It has been shown that cell surface binding of MAbs directed to CD11b or CD18 markedly increases in response to neutrophil stimulation $(3,12,17,18,19)$. This is associated with a concomitant decrease in intracellular granule-associated CD11b, indicating that translocation from intracellular pools to the cell surface occurs in response to stimulation. It has therefore been suggested that increased surface expression of CD11b might be a mechanism that enhances surface adhesiveness $(12,17,18,19)$. Neutrophils from patients undergoing hemodialysis show this same increase in surface $\mathrm{CD} 1 \mathrm{lb}$ and it has been suggested that this may result in leukoaggregation and pulmonary sequestration of granulocytes, thereby accounting for the neutropenia seen in hemodialysis (20).

We found that treatment of neutrophils with the anion channel-blocking agent, DIDS, which is known to inhibit fusion of cytoplasmic granules with the plasma membrane (21-24), effectively blocked increased surface expression of $\mathrm{CD} 1 \mathrm{lb}$ and $\mathrm{CD} 18$ in response to stimulation. This suggests that translocation of $\mathrm{CD} 11 \mathrm{~b}$ and $\mathrm{CD} 18$ from the intracellular pools to the cell surface was similarly blocked. In fact, the amount of surface expression of the CD1lb polypeptide (as assayed by MAb 60.1 binding) after stimulation at $37^{\circ} \mathrm{C}$ was below the level of unstimulated controls. This might be due to an accelerated turnover of receptor in which its replacement from the intracellular granule pool is blocked. The finding that CD18 expression (as assayed by MAb 60.3 binding) did not always parallel $\mathrm{CD} 1 \mathrm{lb}$ expression may be explained by the association of $\mathrm{CD} 18$ with not only $\mathrm{CD} 1 \mathrm{lb}$ (Mac-1), but with CD1 1a (LFA-1) and CD11c (p150,95) as well, whose expression may be regulated by different mechanisms. The effect of DIDS on granule release appears to be relatively specific as DIDS is known not to interfere with other neutrophil functions including superoxide generation and non-complementmediated phagocytosis $(21,22,24)$.

Our results show that when translocation of CD11b and CD18 to the surface of stimulated neutrophils is blocked by DIDS, neutrophil adherence to endothelium is not diminished but is in fact potentiated. This implies that quantitative surface recruitment of CD1 $1 \mathrm{~b}$ and $\mathrm{CD} 18$ from cytoplasmic granules is not the mechanism of enhanced neutrophil adherence to endothelium. The conclusion that increased surface expression of CD11b/CD18 is not causally related to increased adhesiveness is supported by the recent observations that granulocytemonocyte colony stimulating factor increases the surface ex- pression of $\operatorname{CD} 11 \mathrm{~b}(19,37)$ but does not promote adherence to endothelium (37). Further support comes from our observations that neutrophil cytoplasts display increased adherence to endothelium when stimulated, which confirms the observations of Stroncek et al. (38), despite the fact that they do not increase surface expression of CD11b or CD18, which in turn confirms the observations of O'Shea et al. (35) and Petrequin et al. (36). The observation that stimulated cytoplasts adhered less avidly to endothelium compared with intact neutrophils is not surprising since the preparation is much longer and requires many additional steps. Diminished adherence of stimulated cytoplasts compared with intact neutrophils was also observed by Stroncek et al. (38).

These data all indicate that the quantitative increase in surface expression of CD11b and CD18 that follows stimulation is neither sufficient nor necessary to increase neutrophil adherence to endothelium. This suggests the possibility that increased neutrophil adherence after stimulation may be a result of some qualitative alteration of the glycoprotein on the cell surface, such as a conformational change due to phosphorylation, as has been shown to occur with CD18 in peripheral blood mononuclear leukocytes (39). The effect of DIDS in potentiating adherence to endothelium is similar to its observed potentiation of stimulated superoxide generation (21). The mechanism of this potentiation is not clear. In the case of adherence to endothelium, our results indicate that this effect is mediated through CD11b/CD18, yet is not a consequence of increased surface expression of $\mathrm{CD} 1 \mathrm{lb} / \mathrm{CD} 18$, again suggesting the possibility of some qualitative "activation" of the surface glycoprotein(s). Such a qualitative change has been shown to occur with glycoprotein IIb/IIIa in platelets (40) and recent data suggest that IIb/IIIa and the CD11/CD18 complex are part of the same "family" of adherence-mediating cell surface glycoproteins (41).

In contrast to its effect on neutrophil adherence to endothelium, we observed that DIDS inhibited aggregation of stimulated neutrophils. One interpretation of this observation is that recruitment of CD11b and CD18 from an intracellular pool plays an important role in the regulation of neutrophilneutrophil adhesiveness. However, we found, as others have reported, that neutrophil cytoplasts aggregate when stimulated (31), despite the fact that they do not increase surface expression of $\mathrm{CD} 1 \mathrm{lb}(35,36)$. These observations and the recent studies of Philips et al. (42) suggest that, as with adherence to endothelium, increased surface expression of CD1 $1 \mathrm{~b}$ is not the mechanism responsible for aggregation. It is possible that the inhibition of aggregation by DIDS is due to its effects on cell function apart from granule secretion (e.g., ion fluxes, etc.).

The finding that DIDS prevents aggregation but not adherence to endothelium supports Dahinden and Fehr's conclusion that aggregation and adherence are separate phenomena (43). This is further supported by the recent observations that granulocyte-monocyte colony stimulating factor stimulates neutrophil aggregation (20), but does not stimulate adherence to endothelial monolayers (37), whereas tumor necrosis factor- $\alpha$ (TNF- $\alpha$ ) and lipopolysaccharide enhance neutrophil adherence to endotheliym (44) but do not promote neutrophil aggregation (Harlan, J., unpublished observation and reference 43).

The relative importance of the in vitro phenomena of aggregation and adherence as indicators of in vivo pathophysiol- 
ogy is not clear. The recent in vivo demonstration, using intravital microscopy, that blocking chemotaxin-induced neutrophil adherence to microvascular endothelium with MAb 60.3 also prevents neutrophil accumulation and associated plasma leakage (45) indicates that adherence to endothelium is a critical step in the process leading to neutrophil-mediated inflammation. Elucidation of the mechanisms that govern neutrophil adherence to endothelium, therefore, may be crucial to our ability to study and to alter therapeutically neutrophil-mediated inflammation and tissue injury.

\section{Acknowledgments}

We wish to thank Penny Thompson, Käthe Stanness, Arlan Sarkissians, and Paul Mitchell for excellent technical assistance.

This work was supported in part by a grant from the R. J. Nabisco Company and Research grants GM 07037 and HL 18645 from the U. S. Public Health Service. It was performed during the tenure of an Established Investigatorship Award from the American Heart Association (J. M. Harlan).

\section{References}

1. Beatty, P. G., J. M. Harlan, H. Rosen, J. A. Hansen, H. D. Ochs, T. H. Price, R. F. Taylor, and S. J. Klebanoff. 1984. Absence of monoclonal-antibody-defined protein complex in boy with abnormal leukocyte function. Lancet. 1:535-537.

2. Wallis, W. J., D. D. Hickstein, B. R. Schwartz, C. H. June, H. D. Ochs, P. G. Beatty, S. J. Klebanoff, and J. M. Harlan. 1986. Monoclonal antibody-defined functional epitopes on the adhesion-promoting glycoprotein complex (CDw18) of human neutrophils. Blood. 67:1007-1013.

3. Harlan, J. M., P. D. Killen, F. M. Senecal, B. R. Schwartz, E. K. Yee, R. F. Taylor, P. G. Beatty, T. H. Price, and H. D. Ochs. 1985. The role of neutrophil membrane glycoprotein gp-150 in neutrophil adherence to endothelium in vitro. Blood. 66:167-178.

4. Beatty, P. G., J. A. Ledbetter, P. J. Martin, T. H. Price, and J. A. Hansen. 1983. Definition of a common leukocyte cell-surface antigen (Lp95-150) associated with diverse cell-mediated immune functions. $J$. Immunol. 131:2913-2918.

5. Schwartz, B. R., H. D. Ochs, P. G. Beatty, and J. M. Harlan. 1985. A monoclonal antibody-defined membrane antigen complex is required for neutrophil-neutrophil aggregation. Blood. 65:1553-1556.

6. Pohlman, T. H., K. A. Stanness, P. G. Beatty, H. D. Ochs, and J. M. Harlan. 1986. An endothelial cell surface factor(s) induced in vitro by lipopolysaccharide, interleukin 1 , and tumor necrosis factor- $\alpha$ increases neutrophil adherence by a CDw18-dependent mechanism. $J$. Immunol. 136:4548-4553.

7. Arnaout, M. A., R. F. Todd III, N. Dana, J. Melamed, S. F. Schlossman, and H. R. Colten. 1983. Inhibition of phagocytosis of complement $\mathrm{C} 3$ or immunoglobulin G-coated particles and of C3bi binding by monoclonal antibodies to a monocyte-granulocyte membrane glycoprotein (Mo1). J. Clin. Invest. 72:171-179.

8. Anderson, D. C., F. C. Schmalsteig, M. A. Arnaout, S. Kohl, M. F. Tosi, N. Dana, G. J. Buffone, B. J. Hughes, B. R. Brinkley, W. D. Dickey, J. S. Abramson, T. Springer, L. A. Boxer, J. M. Hollers, and C. W. Smith. 1984. Abnormalities of polymorphonuclear leukocyte function associated with a heritable deficiency of high molecular weight surface glycoproteins (gp138): common relationship to diminished cell adherence. J. Clin. Invest. 74:536-551.

9. Arnaout, M. A., J. Pitt, H. J. Cohen, J. Melamed, F. S. Rosen, and H. R. Colten. 1982. Deficiency of a granulocyte-membrane glycoprotein (gp150) in a boy with recurrent bacterial infections. N. Engl. J. Med. 306:693-699.

10. Crowley, C. A., J. T. Curnutte, R. E. Rosin, J. André-Schwartz,
J. I. Gallin, M. Klempner, R. Synderman, R. S. Southwick, T. P. Stossel, and B. M. Babior. 1980. An inherited abnormality of neutrophil adhesion. Its genetic transmission and its association with a missing protein. N. Engl. J. Med. 302:1163-1168.

11. Buchanan, M. R., C. A. Crowley, M. A. Rosin, M. A. Gimbrone, Jr., and B. B. Babior. 1982. Studies on the interaction between gp-180-deficient neutrophils and vascular endothelium. Blood. 60:160-165.

12. Arnaout, M. A., H. Spits, C. Terhorst, J. Pitt, and R. F. Todd III. 1984. Deficiency of a leukocyte surface glycoprotein (LFA-1) in two patients with Mol deficiency. Effects of cell activation on Mol/ LFA-1 surface expression in normal and deficient leukocytes. J. Clin. Invest. 74:1291-1300.

13. Sanchez-Madrid, F., J. A. Nagy, E. Robbins, P. Simon, and T. A. Springer. 1983. A human leukocyte differentiation antigen family with distinct $\alpha$-subunits and a common $\beta$-subunit: the lymphocyte function-associated antigen (LFA-1), the C3bi complement receptor (OKM1/Mac-1), and the p150,95 molecule. J. Exp. Med. 158:17851803.

14. Kürzinger, K., and T. A. Springer. 1982. Purification and structural characterization of LFA-1, a lymphocyte function-associated antigen, and Mac-1, a related macrophage differentiation antigen associated with the type three complement receptor. J. Biol. Chem. 257:12412-12418.

15. Shaw, S. 1987. Characterization of human leukocyte differentiation antigens. Immunol. Today. 8:1-3.

16. Harlan, J. M., B. R. Schwartz, W. J. Wallis, and T. H. Pohlman. 1987. The role of neutrophil membrane proteins in neutrophil emigration. In Leukocyte Emigration and Its Sequelae. H. Z. Movat, editor. Karger Press, Basel, Switzerland. 94-104.

17. Todd, R. F. III, M. A. Arnaout, R. E. Rosin, C. A. Crowley, W. A. Peters, and B. M. Babior. 1984. Subcellular localization of the large subunit of $\mathrm{Mol}\left(\mathrm{Mol}_{\alpha}\right.$; formerly gp1 10), a surface glycoprotein associated with neutrophil adhesion. J. Clin. Invest. 74:1280-1290.

18. Petrequin, P. R., R. F. Todd III, L. J. Devall, L. A. Boxer, and J. T. Curnutte III. 1985. Association between gelatinase release and increased plasma membrane expression of the Mol glycoprotein. Blood. 69:605-610.

19. Arnaout, M. A., E. A. Wang, S. C. Clark, and C. A. Sieff. 1986. Human recombinant granulocyte-macrophage colony-stimulating factor increases cell-to-cell adhesion and surface expression of adhesion-promoting surface glycoproteins on mature granulocytes. J. Clin. Invest. 78:597-601.

20. Arnaout, M. A., R. M. Hakim, R. F. Todd, N. Dana, and H. R. Colten. 1985. Increased expression of an adhesion-promoting surface glycoprotein in the granulocytopenia of hemodialysis. N. Engl. J. Med. 312:457-462.

21. Korchak, H. M., B. A. Eisenstat, S. T. Hoffstein, P. B. Dunham, and G. Weissman. 1980. Anion channel blockers inhibit lysosomal enzyme secretion from human neutrophils without affecting generation of superoxide anion. Proc. Natl. Acad. Sci. USA. 77:2721-2725.

22. Smith, R. J., B. J. Bowman, and S. S. Iden. 1984. Effects of an anion channel blocker, 4,4'-diisothiocyanostilbene-2,2'-disulfonic acid (DIDS), on human neutrophil function. Biochem. Biophys. Res. Commun. 120:964-972.

23. Korchak, H. M., B. A. Eisenstat, J. E. Smolen, L. E. Rutherford, P. B. Dunham, and G. Weissman. 1982. Stimulus-response coupling in the human neutrophil. The role of anion fluxes in degranulation. J. Biol. Chem. 257:6916-6922.

24. Tauber, A. I., and E. J. Goetzl. 1981. Inhibition of complement-mediated functions of human neutrophils by impermeant stilbene disulfonic acids. J. Immunol. 126:1786-1789.

25. Wall, R. T., L. A. Harker, L. J. Quadracci, and G. Striker. 1978. Factors influencing endothelial cell proliferation in vitro. J. Cell. Physiol. 96:203-213.

26. Schwartz, S. M. 1978. Selection and characterization of bovine aortic endothelial cells. In Vitro. 14:966-980. 
27. Thornton, S. C., S. N. Mueller, and E. M. Levine. 1983. Human endothelial cells: use of heparin in cloning and long-term serial cultivation. Science (Wash. DC) 222:623-625.

28. Maciag, T., J. Cerudolo, S. Ilsley, P. R. Kelley, and R. Forand. 1979. An endothelial cell growth factor from bovine hypothalamus: identification and partial characterization. Proc. Natl. Acad. Sci. USA. 76:5674-5678.

29. Böyum, A. 1968. Isolation of mononuclear cells and granulocytes from human blood. Scand. J. Clin. Lab. Invest. 21(Suppl. 97):77-98.

30. Gallin, J. I., R. A. Clark, and H. R. Kimball. 1973. Granulocyte chemotaxis: an improved in vitro assay employing ${ }^{51} \mathrm{Cr}$-labeled granulocytes. J. Immunol. 110:233-240.

31. Korchak, H. M., D. Roos, K. N. Giedd, E. M. Wynkoop, K. Vienne, L. E. Rutherford, J. P. Buyon, A. M. Rich, and G. Weissman. 1983. Granulocytes without degranulation: neutrophil function in granule-depleted cytoplasts. Proc. Natl. Acad. Sci. USA. 80:49684972.

32. Craddock, P. R., D. Hammerschmidt, J. G. White, A. P. Dalmasso, and H. S. Jacob. 1977. Complement (C5a)-induced granulocyte aggregation in vitro. A possible mechanism of complement-mediated leukostasis and leukopenia. J. Clin. Invest. 60:260-264.

33. Lundquist, I., and J-O. Josefsson. 1971. Sensitive method for determination of peroxidase activity in tissue by means of coupled oxidation reaction. Anal. Biochem. 41:567-577.

34. Berger, M., J. O’Shea, A. S. Cross, T. M. Folks, T. M. Chused, E. J. Brown, and M. M. Frank. 1984. Human neutrophils increase expression of $\mathrm{C} 3 \mathrm{bi}$ as well as $\mathrm{C} 3 \mathrm{~b}$ receptors upon activation. J. Clin. Invest. 74:1566-1571.

35. O'Shea, J. J., E. J. Brown, B. E. Seligmann, J. A. Metcalf, M. M. Frank, and J. I. Gallin. 1985. Evidence for distinct intracellular pools of receptors for $\mathrm{C} 3 \mathrm{~b}$ and $\mathrm{C} 3 \mathrm{bi}$ in human neutrophils. J. Immunol. 134:2580-2587.

36. Petrequin, P. R., R. F. Todd III, J. E. Smolen, and L. A. Boxer. 1986. Expression of specific granule markers on the cell surface of neutrophil cytoplasts. Blood. 67:1119-1125.
37. Lopez, A. F., D. J. Williamson, J. R. Gamble, C. G. Begley, J. M. Harlan, S. J. Klebanoff, A. Waltersdorph, G. Wong, S. C. Clark, and M. A. Vadas. 1986. A recombinant human granulocyte-macrophage colony-stimulating factor ( $\mathrm{rH} \mathrm{GM-CSF}$ ) stimulates in vitro mature human neutrophil and eosinophil function, surface receptor expression and survival. J. Clin. Invest. 78:1220-1228.

38. Stroncek, D. F., G. M. Vercellotti, P. W. Huh, and H. S. Jacob. 1986. Neutrophil oxidants inactivate alpha-1-protease inhibitor and promote PMN-mediated detachment of cultured endothelium. Arteriosclerosis. 6:332-340.

39. Hara, T., and S. M. Fu. 1986. Phosphorylation of $\alpha, \beta$ subunits of 180/100-Kd polypeptides (LFA-1) and related antigens. In Leukocyte Typing II, vol. 3. E. L. Reinherz, B. F. Haynes, L. M. Nadler, and I. D. Bernstein, editors. Springer-Verlag, New York. 77-84.

40. Coller, B. S. 1985. A new murine monoclonal antibody reports an activation-dependent change in the conformation and/or microenvironment of the platelet glycoprotein IIb/IIIa complex. J. Clin. Invest. 76:101-108.

41. Hynes, R. O. 1987. Integrins: a family of cell surface receptors. Cell. 48:549-554.

42. Philips, M., J. Buyon, R. Winchester, G. Weissmann, and S. Abramson. 1987. Upregulation of iC $3 \mathrm{~b}$ receptors is neither necessary nor sufficient for aggregation of neutrophils by a chemoattractant. Clin. Res. 35:486A. (Abstr.)

43. Dahinden, C., and J. Fehr. 1983. Granulocyte activation by endotoxin. II. Role of granulocyte adherence, aggregation and effect of cytochalasin B, and comparison with formylated chemotactic peptideinduced stimulation. J. Immunol. 130:863-868.

44. Gamble, J. R., J. M. Harlan, S. J. Klebanoff, and M. A. Vadas. 1985. Stimulation of the adherence of neutrophils to umbilical vein endothelium by human recombinant tumor necrosis factor. Proc. Natl. Acad. Sci. USA. 82:8667-8671.

45. Arfors, K-E., C. Lundberg, L. Lindbom, L. Lundberg, P. G. Beatty, and J. M. Harlan. 1986. A monoclonal antibody to the membrane glycoprotein complex CDw18 (LFA), inhibits PMN accumulation and plasma leakage in vivo. Blood. 69:338-340. 